\title{
EVALUASI PELAKSANAAN PENYULUHAN TERHADAP PETERNAK SAPI PERAH ANGGOTA KUD PUSPA MEKAR BANDUNG BARAT
}

\section{EVALUATION OF EXTENSION IMPLEMENTATION TO DAILY CATTLE FARMERS IN VILLAGE UNIT COOPERATIVE PUSPA MEKAR BANDUNG BARAT MEMBERS}

\author{
Gijanto Purbo Suseno ${ }^{1^{*}}$, Nanik Risnawati ${ }^{1}$, Rossy Anita ${ }^{1}$, Nataliningsih ${ }^{2}$ \\ ${ }^{1}$ Institut Koperasi Indonesia, Sumedang \\ ${ }^{2}$ Universitas Winaya Mukti, Bandung \\ *E-mail corresponding: giyantopurbosuseno@gmail.com
}

\begin{abstract}
ABSTRAK
Koperasi Unit Desa (KUD) Puspa Mekar menaungi anggota yang terdiri dari para peterrnak sapi perah yang berlokasi di kabupaten Bandung Barat, permasalahan yang dihadapi adalah kualitas susu yang dihasilkan belum memenuhi standar yang diharapakan oleh KPBSU, oleh karena itu perlu diteliti bagaimana pelaksanaan penyuluhan yang dilakukan dalam rangka pembinaan para peternak anggota koperasi tersebut. Metode penelitian adalah deskriptif kualitatif, dengan responden sebanyak 32 responden diambil secara random sampling. Hasil penelitian menunjukkan KUD Puspa Mekar merupakan KUD yang bekerja sama dengan KPSBU sebagai Koperasi Susu terbesar, layanan yang dilakukan KUD Puspa Mekar adalah layanan kepada peternak sapi perah, layanan Waserda dan layanan Simpan pinjam . Hasil evaluasi pelaksanaan penyuluhan ditinjau dari tanggapan responden terhadap pelaksanaan penyuluhan adalah baik, harapan responden terhadap unsur penyuluhan adalah penting, sehingga proses penyuluhan ini dapat terus dilakukan sebagai wahana pembinaan terhadap para peternak sapi perah yang menjadi anggota KUD Puspa Mekar.
\end{abstract}

Kata kunci: pangan, ketahanan, strategi, BUMD, Jakarta. SWOT.

\begin{abstract}
Village Unit Cooperative Puspa Mekar (KUD Pusapa Mekar) houses members consisting of dairy workers located in West Bandung regency, the problem faced is the quality of milk produced has not met the standards expected by KPBSU, therefore it needs to be researched how the implementation of extension is carried out in the framework of the development of cooperative member farmers. The research method is qualitative descriptive, with 32 respondents taken at random sampling. The results showed that KUD Puspa Mekar is a KUD in collaboration with KPSBU as the largest Milk Cooperative, the services carried out by KUD Puspa Mekar are services to dairy farmers, Waserda services and Save and Borrow services. The results of the evaluation of the implementation of extensions reviewed from the respondent's response to the implementation of extension are good, the expectation of respondents to the extension element is important, so that this extension process can continue to be done as a vehicle for coaching for dairy farmers who are members of Puspa Mekar KUD.
\end{abstract}

Keywords: Agriculture extension, respondent responses, respondents' expectations 


\section{PENDAHULUAN}

Koperasi KUD Puspa Mekar adalah koperasi yang bergerak di bidang sapi perah yang terletak pada Jalan Kolonel Masturi RT 02/15 No. 20 Desa Cihideung, Kecamatan Parongpong, Kabupaten Bandung Barat. KUD Puspa Mekar berbadan hukum nomor 8804/BH/PAD/KWK-10/VI/1998.

Koperasi KUD Puspa Mekar termasuk jenis koperasi produsen yang berdiri pada tahun 1998. Dalam upaya memenuhi kebutuhan anggota KUD Puspa Mekar menyediakan pelayanan - pelayanan pada unit usaha dan pelayanan, adapun unit - unit usaha dan pelayanan yang ada di KUD Puspa Mekar yaitu : 1. Unit Produksi Susu, Pemasaran dan Kualitas Susu 2. Unit Waserda 3. Unit Pakan Konsentrat 4. Unit Penyakuran Kredit Sapi 5. Unit Pelayanan Keswan dan Inseminasi Buatan 6. Unit Pelayanan Keuangan Unit usaha produksi susu merupakan pilar bisnis utama KUD Puspa Mekar. Seluruh anggota KUD Puspa Mekar merupakan peternak sapi perah. Kegiatan yang dilaksanakan dalam unit produksi susu meliputi pelayanan kesediaan pakan ternak, pelayanan kesehatan dan Inseminasi Buatan (IB) ternak, upaya untuk menjaga kualitas susu yang dihasilkan anggota agar harga yang diterima anggota selalu meningkat dan pemasaran susu yang dihasilkan ke
Industri Pengolaan Susu (IPS). Peningkatan produksi dan kualitas susu sangat penting karena kualitas susu merupakan aspek yang sangat diperhatikan oleh konsumen dan juga nilai tambah untuk peternak. Susu yang berkualitas baik berpengaruh terhadap harga jual yaitu semakin bagus kualitas susu maka harga jualnya pun semakin tinggi. Menurut Ditjen Perternakan (2014), produktivitas susu dan kualitas susu dapat dilihat dari tatacara berternak yang dilakukan dengan menjaga kesehatan sapi perah, kebersihan kandang, dan kebersihan peralatan untuk pemerahan susu, prosedur pemerahan yang benar, pemberian pakan dan minum yang sesuai dengan kebutuhan. Sapi yang dipelihara dengan manajemen yang baik akan menghasilkan produksi susu yang banyak dan berkualitas baik. Aspek manajemen pemeliharaan memegang peranan penting dalam meningkatkan produktivitas ternak.

Tata laksana pada perternakan sapi mempunyai peran sangat penting, menyangkut bagaimana perencanaan dan pemeliharaan sapi perah sehingga akan dapat tercapai produksi susu yang berkualitas sangat baik. Kunci utama yang menitik beratkan berhasilnya pemeliharaan sapi perah ialah pemeliharaannya. 
Tabel 1. Produksi Susu di KUD Puspa Mekar

\begin{tabular}{cccccrrr}
\hline No & Tahun & \multicolumn{3}{c}{ Jumlah } & \multicolumn{3}{c}{ Populasi ternak (ekor) } \\
& & $\begin{array}{c}\text { Anggota } \\
\text { (orang) }\end{array}$ & $\begin{array}{c}\text { Produksi } \\
\text { (liter) }\end{array}$ & $\begin{array}{c}\text { Laktasi } \\
\text { /KK }\end{array}$ & Dara & Anak & Jumlah \\
\hline 1 & 2016 & 535 & 4.336 .333 & 1.103 & 218 & 390 & 1.711 \\
2 & 2017 & 577 & 5.045 .255 & 1.123 & 352 & 301 & 1.776 \\
3 & 2018 & 661 & 5.423 .157 & 1.203 & 350 & 318 & 1.871 \\
4 & 2019 & 655 & 5.694 .000 & 1.254 & 361 & 325 & 1.940 \\
5 & 2020 & 640 & 5.986 .250 & 1.234 & 354 & 311 & 1.899 \\
& Jumlah & 3.068 & 26.484 .995 & 5.917 & 1.635 & 1.642 & 9.197 \\
\hline
\end{tabular}

Sumber : Laporan RAT KUD Puspa Mekar

Pemeliharaan sapi perah masih dilakukan secara tradisional, dengan kondisi susu masih terpapar antibiotic, kualitas susu masih dibawah standar dengan kandungan bakteri (TPC $>1.500 .000 / \mathrm{ml}$ ), $\mathrm{pH}$ 6,8 dan Total Solid (TS1/-11,85 \%), dan kadar lemak 2,8 \% (sumber RAT 2017), sehingga kualitas susu masih dianggap rendah. Untuk memperbaiki kualitas susu peternak maka KUD Puspa Mekar bekerja sama dengan penyuluh peternakan melakukan pembinaan cara pemeliharaan sapi perah kepada anggotanya.

Permasalahan yang dihadapi para peternak dalam pemeliharaan sapi perah antara lain : pembibitan dan reproduksi, pakan ternak dan air minum, pemeliharaan, kandang dan peralatan, dan kesehatan ternak. Menghadapi permasalahan tersebut maka KUD Puspa Mekar mengambil jalan keluar yaitu memberikan penyuluhan, bekerja sama dengan Dinas Peternakan Propinsi jawa Barat , diharapkan pelaksanaan penyuluhan dapat merubah pengetahuan, sikap dan ketrampilan anggota dalam teknik pemeliharaan sapi perah. Fasilitasi jaringan pembelajaran dapat berfungsi untuk mencapai penyuluhan pertanian yang efisien yang menghubungkan petani lintas jarak untuk pembelajaran konstruktivis. Untuk mewujudkan manfaat ini, perancang jaringan pembelajaran perlu mempertimbangkan desain himpunan, desain sosial, dan desain epistemic (Kelly et al., 2017), sehingga proses pembelajaran dalan kegiatan penyuluhan dapat efektif. 
EVALUASI PELAKSANAAN PENYULUHAN TERHADAP PETERNAK SAPI PERAH ANGGOTA KUD PUSPA MEKAR BANDUNG BARAT

Gijanto Purbo Suseno, Nanik Risnawati, Rossy Anita, Nataliningsih

Tabel 2. Perencanaan Dan Pelaksanaan Penyuluhan

\begin{tabular}{cccll}
\hline No & Tahun & & Perencanaan & Pelaksanaan \\
\hline 1 & 2016 & 4 kali & 3 kali \\
2 & 2017 & 4 kali & 2 kali \\
3 & 2018 & 4 kali & 3 kali \\
4 & 2019 & 4 kali & 3 kali \\
5 & 2020 & 4 kali & 2 kali \\
\hline
\end{tabular}

Sumber : Laporan RAT KUD Puspa mekar 2021

Penyuluhan menjadi sarana memberikan pengetahuan, sikap dan ketrampilan bagi peternak sapi perah agar kualitas susu yang dihasilkan menjadi lebih baik dan memenuhi kualiitas standar yang diharapkan KUD. Hasil penelitian Maharani D., 2020, "Hubungan antara Pelaksanaan Kegiatan Penyuluhan dengan Tindakan Peternak sapi Perah untuk Peningkatan Produksi dan Kualitas Susu “, hasilnya tingakta pelaksanaan penyuluhan dengan tindakan peternak dalam teknis pemeliharaan sapi memiliki hubungan positif. Hal ini menginspirasi apakah pelaksanaan penyuluhan berdampak pada teknik pemeliharan sapi dan pemahaman anggota agar kualitas susunya memenuhi standar KUD Puspa Mekar.

\section{METODE PENELITIAN}

Penelitian ini dilakukan di KUD Puspa Mekar Kabupaten Bandung Barat, mulai bulan januari sampe Juni 2021, dengan pendekatan deskriptif kualitatif. Data yang dibutuhkan yaitu data primer bersumber dari kelompok peternak sapi perah yang menjadi anggota KUD Puspa Mekar dan data sekunder diperoleh dari
KUD Puspa Mekar. Instrumen yang digunakan adalah kuesioner menggunakan skala Likert )yang ditujukan kepada kelompok peternak sapi perah untuk menilai pelaksanaan penyuluhan yang diperoleh. Pengambilan sampel secara purposive sampling, sebanyak $5 \%$ dari total anggota yaitu $5 \%$ dari 640 , total responden yakni 32 orang. Data yang diambil yaitu tanggapan dan harapan anggota kelompok ternak sapi perah dan unsur penyuluhan.

\section{HASIL DAN PEMBAHASAN}

\section{Gambaran Umum KUD Puspa Mekar}

KUD Puspa Mekar berlokasi di Kabupaten Bandung Barat, yang bergabung dengan GKSI (Gabungan Koperasi Susu Indoensia ) Jawa Barat sejak bulan Mei 2006. Kemudian bergabung dengan KPSBU (Koperasi Susu Bandung Utara) untuk pengembangan koperasinya. Struktur organisasi terdiri pengurus yaitu Ketua koperasi yaitu H Djatnika SE, sekretaris yaitu Mahmud Hidayat S.St, Bendahara yaitu Jajang jajuli, Ketua pengawas yaitu Sami Mulyana, Anggota pengawas yaitu Acep M. Husni , anggota pengawas yaitu Asep Karyana. Total karyawan adalah 22 
orang, total anggota 640 orang. Kegiatan koperasi antara lain :

a. Unit produksi susu dan pemasaran susu
Hasil wawancara dan melihat data sekunder diperoleh informasi volume produksi dan pendapatan susu KUD Puspa mekar adalah sebagai berikut :

Tabel 3. Volume Produksi Dan Pendapatan Susu

\begin{tabular}{rrrr}
\hline Tahun & Produksi (liter) & $\begin{array}{c}\text { Kenaikan produksi } \\
\text { (liter ) }\end{array}$ & \multicolumn{1}{c}{ Pendapatan (Rp) } \\
\hline 2016 & 4.336 .333 & & $4.128 .150 .224,30$ \\
2017 & 5.045 .255 & 708.922 & $4.957 .997 .644,80$ \\
2018 & 5.423 .157 & 377.902 & $5.270 .939 .484,60$ \\
2019 & 5.694 .000 & 270.843 & $5.439 .162 .667,20$ \\
2020 & 5.986 .250 & 292.250 & $6.018 .850 .316,40$ \\
\hline
\end{tabular}

Sumber : Laporan RAT KUD Puspa Mekar 2021

b. Warung Serba Ada (WASERDA)

Koperasi Puspa Mekar mengelola warung serba ada untuk memenuhi kebutuhan anggota dalam bidang kebutuhan rumah tangga dan kebutuhan ternaknya sehingga jika peternak membutuhkan pakan ternak dapat membeli pecan konsentrat di koperasi.

c. Unit Simpan Pinjam

Pelayanan simpan pinjam muali dilakukan tahun2007, dengan ketentuan, jumlah pinjaman kepada anggota tidak diperbolehkan cicilannya melebihi jumlah bayaran susu anggota per 15 hari atau tidak diperkenankan melebihi Rp 20.000.000,--

Berdasarkan data diatas menunjukkan adanya kenaikan produksi susu setiap tahunnya, walaupun belum stabil dan pada tahun terakhir terjadi penurunan karena dampak pandemic covid-19. Tugas KUD Puspa Mekar untuk terus memberi pelayanan sebaik mungkin kepada anggotanya agar produksi susu meningkat serta kualitas susu memenuhi standar. Hasil penelitian Suarta , 2020, menunjukkan bahwa tingkat komunikasi, intensitas komunikasi, dan kinerja koperasi peternakan di Provinsi Bali masih kurang. Jika dilihat dari faktorfaktor yang mempengaruhi, maka variabel karakteristik responden, komunikasi, dan intensitas komunikasi berpengaruh positif dan signifikan terhadap kinerja koperasi peternakan di Provinsi Bali (Suarta et al., 2020). Oleh karena itu KUD Puspa Mekar harus terus berkreasi dalam pelayanan kepada anggotanya , pelaksanaan experiental learning berdasarkan konsep tanggung jawab bersama mendorong peningkatan keterampilan kewirausahaan dan koperasi serta kemampuan anggota untuk membayar angsuran pinjaman pada koperasi secara tepat waktu (GP Suseno and Nataliningsih, 2017), konsep ini dapat diterapkan agar jumlah sapi 
EVALUASI PELAKSANAAN PENYULUHAN TERHADAP PETERNAK SAPI PERAH ANGGOTA KUD PUSPA MEKAR BANDUNG BARAT

Gijanto Purbo Suseno, Nanik Risnawati, Rossy Anita, Nataliningsih

semakin meningkat yang berdampak jumlah setoran susu semakin meningkat.

\section{Pelaksanaan Penyuluhan tentang} Teknik Pemeliharaan Sapi Perah

a. Pelaksanaan penyuluhan dipantau secara langsung oleh pengawas koperasi secara langsung berkomunikasi dengan para peternak sapi. Terdapat 3 penyuluh yang ditugaskan di Koperasi Puspa Mekar dengan tingkat pendidikan Sarjana strata 1, dan pengalaman sebagai penyuluh bervariasi antara 9 sampe 22 tahun.

b. Materi penyuluhan yang disampaikan meliputi : 1) Teknis pemerasan susu yang benar, 2) Cara pemilihan dan pemberian pakan ternak, 3) kesehatan hewan ternak.

c. Sasaran penyuluhan, adalah anggota koperasi sebanyak 644 orang yang dibagi dalam 32 kelompok, sehingga jadwal pelaksanaan penyuluhan sangat padat yaitu 3-6 bulan sekali.

d. Media penyuluhan yang digunakan adalah alat peraga gambar, karton kerja, pemutaran video, dan buku panduan yang diberikan kepada anggota.

Perspektif kompetensi dan motivasi berpengaruh positif terhadap kinerja penyuluh, sedangkan perspektif lingkungan kerja tidak berpengaruh terhadap kinerja penyuluh (Nataliningsih, Gijanto Purbo Suseno, Sugiyanto, 2020), penyuluh peternakan sapi perah sebaiknya mengatur jadwal peyuluhan dan pengkondisian waktu penyuluhan agar sesuai kebutuhan peternak dan siap diimplementasikan dalam kegiatan pemeliharaan ternaknya, dampaknya sesuai harapan yaitu memperbaiki kualitas susu sapi yang dihasilkan. Keberhasilan penyuluhan tergantung pula pada kebijakan pemerintah yang berpihak pada penyuluh sehingga penyuluh melaksanakan tugas dengan baik, pemerintah dan lembaga donor dalam beberapa dekade terakhir berusaha untuk memajukan perbaikan struktural, keuangan, kelembagaan, dan manajerial untuk layanan penyuluhan pertanian (Bitzer, 2016).

Hasil penelitian lain menunjukkan bahwa kinerja Koperasi Peternak Susus Bogor termasuk dalam kategori kurang sehat (BBB) dengan total skor 53,4\% sehingga perbaikan kinerja pada setiap perspektif baik finansial maupun non finansial sangat perlu dilakukan (Purwono et al., 2013)

\section{Tanggapan anggota Terkait}

\section{Pelaksanaan Penyuluhan}

Total responden ada 32 orang yang memberi tanggapan terhadap kuesioner yang diberikan, hasil analisis terhadap kuesioner disajikan pada gambar 1. Unsur penyuluhan yang dinilai antara lain peran penyuluh, materi penyuluhan, sasaran penyuluhan, 
metode penyuluhan, media penyuluhan yang digunakan, waktu pelaksanaan penyuluhan, tempat pelaksanaan penyuluhan, , pengetahuan penyuluh yang dikuasai, sikap penyuluh dan ketrampilan penyuluh . Rataan nilai tanggapan responden terhadap unsur penyuluhan dan hasilnya adalah sebagai berikut :

Tabel 3. Rata Rata Tanggapan Responden Terhadap Unsur Penyuluhan

\begin{tabular}{|c|c|c|c|}
\hline No & indikator & Skor & Kriteria \\
\hline 1 & Kemampuan dalam menyampaikan materi & 129 & Baik \\
\hline 2 & Kemampuan penyuluh membimbing peserta & 127 & Baik \\
\hline 3 & $\begin{array}{l}\text { Kemampuan penyuluh memecahkan } \\
\text { permasalahan dan memberi solusi }\end{array}$ & 131 & Baik \\
\hline 4 & $\begin{array}{l}\text { Keseuaian materi penyuuhan dengan kebutuhan } \\
\text { peserta }\end{array}$ & 110 & Baik \\
\hline 5 & $\begin{array}{l}\text { Kejelasan materi penyuluhan yang diterima } \\
\text { peserta }\end{array}$ & 127 & Baik \\
\hline 6 & $\begin{array}{l}\text { Kemudahan materi penyuluhan untuk } \\
\text { dilaksankan }\end{array}$ & 117 & Baik \\
\hline 7 & Kemampuan peserta dalam menerima materi & 124 & Baik \\
\hline 8 & Kehadiran peserta dalam penyuluhan & 124 & Baik \\
\hline 9 & Keaktifan peserta & 119 & Baik \\
\hline 10 & Tingkat pengetahuan peserta & 111 & Baik \\
\hline 11 & Keseuaian metode dan teknik penyuluhan & 135 & Baik \\
\hline 12 & Kesuaian media penyuluhan & 118 & Baik \\
\hline 13 & Kesuaian waktu dan jadwal penyuluhan & 125 & Baik \\
\hline 14 & Keseuaian waktu dengan peserta penyuluhan & 118 & Baik \\
\hline 15 & Ketepatan dalam memilih tempat & 116 & Baik \\
\hline 16 & Meningkatnya pengetahuan peserta & 124 & Baik \\
\hline 17 & Pengembangan sikap peserta & 135 & Baik \\
\hline 18 & Peningkatan ketrampilan peserta & 116 & Baik \\
\hline
\end{tabular}

Temuan menunjukkan perbedaan antara pengalaman kerja dan kualifikasi penyuluh yang dapat menyiratkan kurangnya kualitas pengetahuan, informasi dan keterampilan yang diberikan kepada petani/peternak (Moyo \& Salawu, 2018). Penyuluh telah mempunyai pengalaman 9-22 tahun sehingga pelaksanaan penyuluhan dinilai baik oleh responden . Untuk meningkatkan keterserapan materi penyuluhan maka perlu ada ketua kelompok peternak sapi perah yang bertanggung jawab membina anggota nya , ketika heterogenitas dan jenis ketua kelompok dibentuk, hasil menunjukkan bahwa kualitas ketua kelompok, perilaku adopsi ketua kelompok, dan pelatihan reguler ketua kelompok memiliki efek yang kuat dan konsisten pada kesadaran 
EVALUASI PELAKSANAAN PENYULUHAN TERHADAP PETERNAK SAPI PERAH ANGGOTA KUD PUSPA MEKAR BANDUNG BARAT

Gijanto Purbo Suseno, Nanik Risnawati, Rossy Anita, Nataliningsih

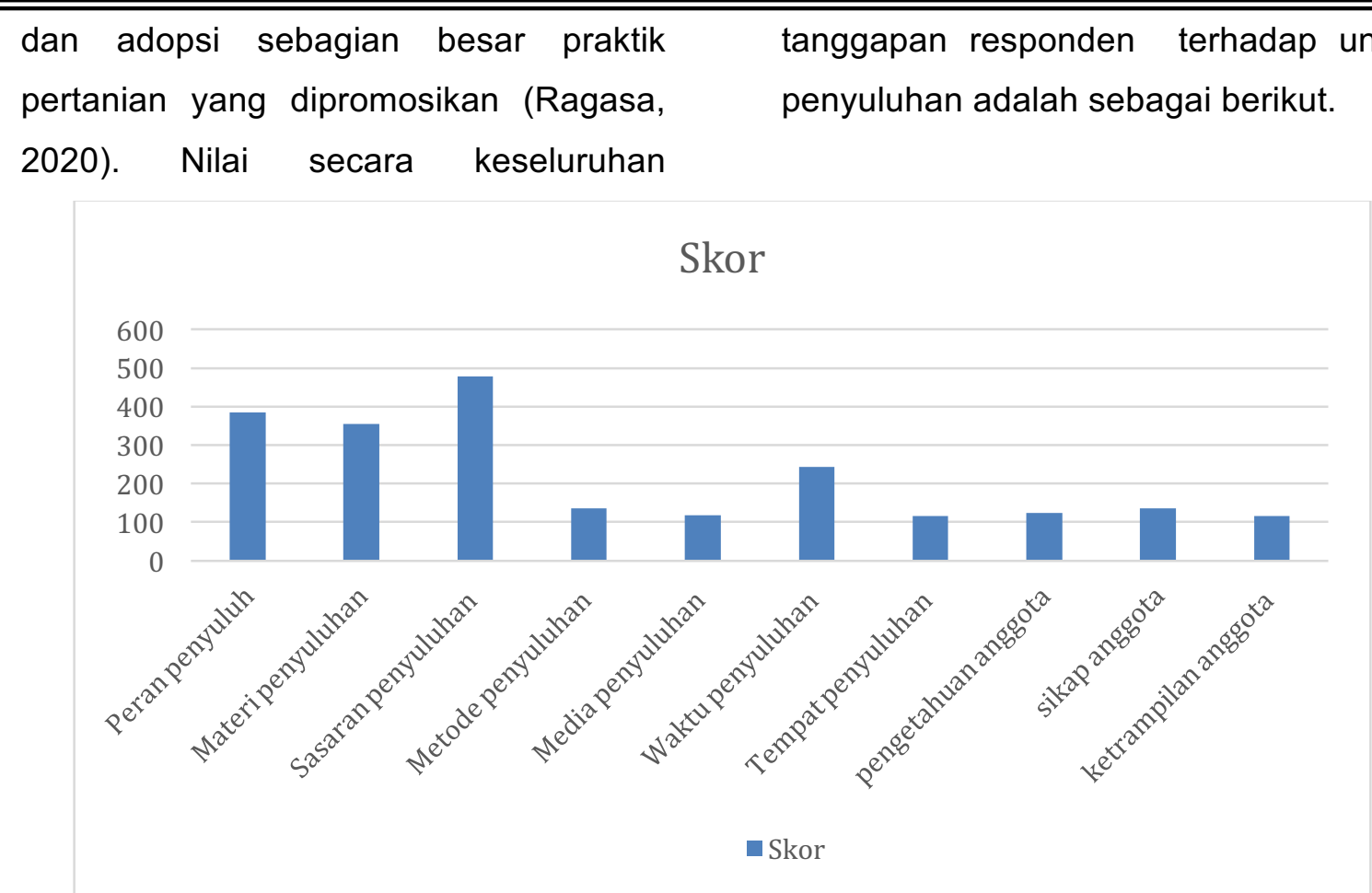

\section{Gambar 1. Kurva Hasil Penilaian Tanggapan Responden Terhadap Unsur Penyuluhan}

Transfer pengetahuan dari penyuluh kepada peternak ini terjadi baik secara horizontal kepada anggota masyarakat maupun secara vertikal melalui hubungan dengan penyuluh, lembaga penelitian dan kepentingan sektor swasta, transfer ini memiliki dampak penting pada efisiensi dan kesetaraan (Taylor \& Bhasme, 2018). Palaksanaan penyuluhan yang baik hasilnya akan meningkatkan ketrampilan peternak sapi perah dan dampaknya adalah peningkatan kualitas susu yang diterima KUD. Persepsi peternak terhadap penyuluhan berkorelasi positif secara signifikan dengan tingkat partisipasi peternak dalam penyuluhan.
Demikian pula tingkat partisipasi peternak dalam penyuluhan berkorelasi positif secara signifikan dengan kinerja usaha (Syahdar Baba, Isbandi, 2011).

\section{Evaluasi Harapan Anggota Terhadap Unsus-unsur Penyuluhan}

Hasil rataan harapan responden terhadap unsur-unsur pelaksanaan penyuluhan pada Tabel 4. Studi ini menemukan bahwa mode penyuluhan teknologi pertanian baru meningkatkan tingkat adopsi teknologi petani sampai batas tertentu dengan efek limpahan parsial, dan petani dari berbagai usia dan dengan ukuran lahan pertanian yang berbeda mendapat manfaat yang berbeda. 
Tabel 4. Rata Rata Harapan Responden Terhadap Unsur Penyuluhan

\begin{tabular}{|c|c|c|c|}
\hline No & indikator & Skor & Kriteria \\
\hline 1 & Kemampuan dalam menyampaikan materi & 131 & Penting \\
\hline 2 & Kemampuan penyuluh membimbing peserta & 130 & Penting \\
\hline 3 & $\begin{array}{l}\text { Kemampuan penyuluh memecahkan } \\
\text { permasalahan dan memberi solusi }\end{array}$ & 133 & Penting \\
\hline 4 & $\begin{array}{l}\text { Keseuaian materi penyuuhan dengan kebutuhan } \\
\text { peserta }\end{array}$ & 123 & Penting \\
\hline 5 & $\begin{array}{l}\text { Kejelasan materi penyuluhan yang diterima } \\
\text { peserta }\end{array}$ & 127 & Penting \\
\hline 6 & $\begin{array}{l}\text { Kemudahan materi penyuluhan untuk } \\
\text { dilaksankan }\end{array}$ & 181 & Penting \\
\hline 7 & Kemampuan peserta dalam menerima materi & 129 & Penting \\
\hline 8 & Kehadiran peserta dalam penyuluhan & 132 & Penting \\
\hline 9 & Keaktifan peserta & 128 & Penting \\
\hline 10 & Tingkat pengetahuan peserta & 130 & Penting \\
\hline 11 & Keseuaian metode dan teknik penyuluhan & 134 & Penting \\
\hline 12 & Kesuaian media penyuluhan & 134 & Penting \\
\hline 13 & Kesuaian waktu dan jadwal penyuluhan & 110 & Penting \\
\hline 14 & Keseuaian waktu dengan peserta penyuluhan & 127 & Penting \\
\hline 15 & Ketepatan dalam memilih tempat & 128 & Penting \\
\hline 16 & Meningkatnya pengetahuan peserta & 130 & Penting \\
\hline 17 & Pengembangan sikap peserta & 134 & Penting \\
\hline 18 & Peningkatan ketrampilan peserta & 98 & Cukup Penting \\
\hline
\end{tabular}

Ketika membimbing petani untuk menggunakan mode penyuluhan teknologi pertanian yang baru, penting untuk mempertimbangkan difusi informasi di antara petani yang telah mengadopsi mode ini dan untuk menyebarkan informasi ini kepada petani tua dan petani skala kecil (Gao et al., 2020). Hasil evaluasi nilai skor harapan responden terhadap unsur penyuluhan dapat digambarkan sebagai berikut :

\section{Skor}

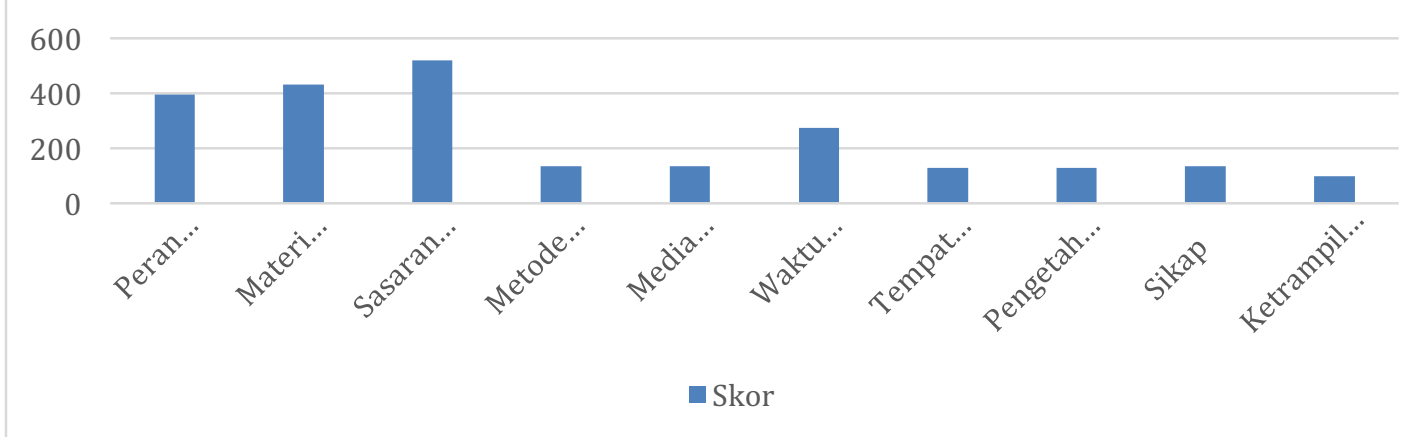

Gambar 2. Evaluasi Nilai Skor Harapan Responden Terhadap Unsur Penyuluhan 
EVALUASI PELAKSANAAN PENYULUHAN TERHADAP PETERNAK SAPI PERAH ANGGOTA KUD PUSPA MEKAR BANDUNG BARAT

Gijanto Purbo Suseno, Nanik Risnawati, Rossy Anita, Nataliningsih

\begin{abstract}
Perilaku adopsi petani kecil terutama dibentuk oleh norma dan kepercayaan sosial masyarakat yang ada yang cenderung mendorong pertukaran pengetahuan, yang bertentangan dengan pendekatan penyuluhan transfer pengetahuan konvensional. Oleh karena itu, norma merupakan bagian yang tidak terpisahkan dari sistem sosial dan dapat menciptakan praktik, kebiasaan, dan standar pertanian yang berbeda dalam suatu kelompok sosial. Peneliti dan penyuluh dapat bertindak berdasarkan sikap positif yang teridentifikasi ini, 13 norma dan kontrol perilaku yang dirasakan untuk menjamin adopsi dan keberlanjutan teknologi pertanian
\end{abstract} (Buyinza et al., 2020)

Kinerja penyuluh menjadi harapan KUD agar para peternak dapat meningkatkan perbaikan terhadap pemeliharaan ternaknya, pelaksanaan penyuluhan ini merupakan salah satu bentuk layanan KUD kepada anggota agar memuaskan anggotanya. Berdasarkan pengukuran Tingkat Kepuasan Anggota KUD Setia terhadap administrasi koperasi, budaya kerja pengurus, keuangan koperasi, usaha RMU, usaha simpan pinjam dan usaha penagihan rekening listrik dan PDAM, diperoleh nilai rata-rata kepuasan anggota sebesar 76,55 persen dengan kriteria baik (Karni et al., 2011). Perlu ditingkatkan terus kinerja penyuluh, studi ini merekomendasikan pengembangan program pelatihan profesional berdasarkan pengetahuan penyuluh saat ini (Alotaibi et al., 2019)

\section{KESIMPULAN}

Berdasarkan hasil penelitian dapat disimpulkan

1. KUD Puspa Mekar mengelola peternak sapi perah Kabupaten Bandung barat yang menjadi anggota koperasinya dengan layanan yaitu layanan kebutuhan peternakan/ pakan /konsentrat ternak , layanan Warung serba ada kebutuhan anggota, dan layanan simpan pinjam

2. Tanggapan anggota koperasi yaitu para peternak sapi perah terhadap pelaksanaan penyuluhan adalah baik

3. Harapan anggota koperasi yaitu para peternak sapi perah terhadap pelaksanaan penyuluhan adalah penting.

\section{DAFTAR PUSTAKA}

Alotaibi, B. A., Yoder, E., Brennan, M. A., \& Kassem, H. S. (2019). Training needs of extension agents' regarding organic agriculture in Saudi Arabia. Evaluation and Program Planning, 77(July). https://doi.org/10.1016/i.evalprogpl an.2019.101711

Bitzer, V. (2016). Incentives for enhanced performance of agricultural 
extension systems. Kit Suistanable Economic Development \& Gender, $6,1-8$.

Buyinza, J., Nuberg, I. K., Muthuri, C. W., \& Denton, M. D. (2020). Assessing smallholder farmers' motivation to adopt agroforestry using a multigroup structural equation modeling approach. Agroforestry Systems, 94(6), 2199-2211. https://doi.org/10.1007/s10457020-00541-2

Gao, Y., Zhao, D., Yu, L., \& Yang, H. (2020). Influence of a new agricultural technology extension mode on farmers' technology adoption behavior in China. Journal of Rural Studies, 76(August 2019), 173-183.

https://doi.org/10.1016/j.jrurstud.20 $\underline{20.04 .016}$

GP Suseno and Nataliningsih. (2017). Experiential Learning Implementation Based on Joint Responsibilityin Women's Cooperative Development (Case Study onFarmer Women Cooperative, Sumedang,West Java). GCEE Conference Proceedings, 1887(1 September 2017), 020025.

Karni, W., Pertanian, F., \& Andalas, U. (2011). Analisis Kinerja Koperasi Unit Desa ( Kud ) Setia Nagari Selayo Kecamatan Kubung Analisis Kinerja Koperasi Unit Desa ( Kud) Setia Nagari Selayo Kecamatan Kubung.

Kelly, N., Bennett, J. M. L., \& Starasts, A. (2017). Networked learning for agricultural extension: a framework for analysis and two cases. Journal of Agricultural Education and Extension, 23(5), 399-414. https://doi.org/10.1080/1389224X.2 017.1331173
Moyo, R., \& Salawu, A. (2018). A survey of communication effectiveness by agricultural extension in the Gweru district of Zimbabwe. Journal of Rural Studies, 60(11), 32-42. https://doi.org/10.1016/j.jrurstud.20 $\underline{18.03 .002}$

Nataliningsih, Gijanto Purbo Suseno, Sugiyanto, and F. K. G. (2020). Agricultural Extension Performance Reviewed From the Perspective of Competence, Motivation and Work Environment. International Journal of Psychosocial Rehabilitation, 24(6), 12187-12194. https://doi.org/10.37200/IJPR

Purwono, J., Sugyaningsih, S., \& Roseriza, A. (2013). Analisis Kinerja Koperasi Produksi Susu dengan Pendekatan Balanced Scorecard. Neo-Bis, 7(1), 1-16.

Ragasa, C. (2020). Effectiveness of the lead farmer approach in agricultural extension service provision: Nationally representative panel data analysis in Malawi. Land Use Policy, $\quad$ 99(July), 104966. https://doi.org/10.1016/i.landusepol .2020 .104966

Suarta, G., Suparta, N., Bidura, I. G. N. G., \& Putri, B. R. T. (2020). Effective communication models to improve the animal cooperatives performance in Bali-Indonesia. International Journal of Pharmaceutical Research, 12(4), 3776-3785.

https://doi.org/10.31838/ijpr/2020.1 2.04 .513

Syahdar Baba, Isbandi, T. M. Dan W. (2011). DALAM PENYULUHAN TERHADAP KINERJA USAHA PETERNAK SAPI PERAH DI KABUPATEN ENREKANG ( Effect of Perception and Participation in Extension Activities on Diary Cattle Farming Performance in Enrekang 
EVALUASI PELAKSANAAN PENYULUHAN TERHADAP PETERNAK SAPI PERAH ANGGOTA KUD PUSPA MEKAR BANDUNG BARAT

Gijanto Purbo Suseno, Nanik Risnawati, Rossy Anita, Nataliningsih

). Nasional Teknologi Peternakan Dan Veteriner 2011, 208-216.

Taylor, M., \& Bhasme, S. (2018). Model farmers, extension networks and the politics of agricultural knowledge transfer. Journal of Rural Studies, 64(August), 1-10. https://doi.org/10.1016/j.jrurstud.20 18.09.015 